\title{
Fixed point theorems for Kannan-type maps
}

\section{Jeong Sheok Ume*}

\section{*Correspondence:} jsume@changwon.ac.kr

Department of Mathematics, Changwon National University,

Changwon, 641-773, Korea

\begin{abstract}
We introduce the new classes of Kannan-type maps with respect to u-distance and prove some fixed point theorems for these mappings. Then we present several examples to illustrate the main theorems.
\end{abstract}

\section{Introduction}

A mapping $T$ on a metric space $(X, d)$ is called Kannan if there exists $\alpha \in\left[0, \frac{1}{2}\right)$ such that

$$
d(T x, T y) \leq \alpha d(x, T x)+\alpha d(y, T y)
$$

for all $x, y \in X$. Kannan [1] proved that if $X$ is complete, then a Kannan mapping has a fixed point. It is interesting that Kannan's theorem is independent of the Banach contraction principle [2]. Also, Kannan's fixed point theorem is very important because Subrahmanyam [3] proved that Kannan's theorem characterizes the metric completeness. That is, a metric space $X$ is complete if and only if every Kannan mapping on $X$ has a fixed point.

Using the concept of Hausdorff metric, Nadler [4] proved the fixed point theorem for multi-valued contraction maps, which is a generalization of the Banach contraction principle [2]. Since then various fixed point results concerning multi-valued contractions have appeared; for example, see [5-7] and the references cited there.

Without using the concept of Hausdorff metric, most recently Dehaish and Latif [8] generalized fixed point theorems of Latif and Abdou [9], Suzuki [10], Suzuki and Takahashi [11].

In 1996, Kada et al. [12] introduced the notion of $w$-distance and improved several classical results including Caristi's fixed point theorem. Suzuki and Takahashi [11] introduced single-valued and multi-valued weakly contractive maps with respect to $w$-distance and proved fixed point results for such maps. Generalizing the concept of $w$-distance, in 2001, Suzuki [10] introduced the notion of $\tau$-distance on a metric space and improved several classical results including the corresponding results of Suzuki and Takahashi [11]. In 2010, Ume [13] introduced the new concept of a distance called $u$-distance, which generalizes $w$-distance, Tataru's distance and $\tau$-distance. Then he proved a new minimization theorem and a new fixed point theorem by using $u$-distance on a complete metric space.

Distances in uniform spaces were given by Vályi [14]. More general concepts of distances were given by Wlodarczyk and Plebaniak [15-18] and Wlodarczyk [19].

In this paper, we introduce the new classes of Kannan-type multi-valued maps without using the concept of Hausdorff metric and Kannan-type single-valued maps with respect 
to $u$-distance and prove some fixed point theorems for these mappings. Then we present several examples to illustrate the main theorems.

\section{Preliminaries}

Throughout this paper we denote by $N$ the set of all positive integers, by $R$ the set of all real numbers and by $R_{+}$the set of all nonnegative real numbers.

Ume [13] introduced $u$-distance as follows: Let $X$ be metric space with metric $d$. Then a function $p: X \times X \rightarrow R_{+}$is called $u$-distance on $X$ if there exists a function $\theta: X \times X \times$ $R_{+} \times R_{+} \rightarrow R_{+}$such that the following hold for $x, y, z \in X$ :

$\left(u_{1}\right) p(x, z) \leq p(x, y)+p(y, z)$.

$\left(u_{2}\right) \theta(x, y, 0,0)=0$ and $\theta(x, y, s, t) \geq \min \{s, t\}$ for all $x, y \in X$ and $s, t \in R_{+}$, for any $x \in X$ and for every $\varepsilon>0$, there exists $\delta>0$ such that $\left|s-s_{0}\right|<\delta,\left|t-t_{0}\right|<\delta, s, s_{0}, t, t_{0} \in R_{+}$and $y \in X$ imply $\left|\theta(x, y, s, t)-\theta\left(x, y, s_{0}, t_{0}\right)\right|<\varepsilon$.

$\left(u_{3}\right) \lim _{n \rightarrow \infty} x_{n}=x$ and $\lim _{n \rightarrow \infty} \sup \left\{\theta\left(w_{n}, z_{n}, p\left(w_{n}, x_{m}\right), p\left(z_{n}, x_{m}\right)\right): m \geq n\right\}=0$ imply $p(y, x) \leq \lim _{n \rightarrow \infty} \inf p\left(y, x_{n}\right)$ for all $y \in X$.

(u $\left.u_{4}\right) \lim _{n \rightarrow \infty} \sup \left\{p\left(x_{n}, w_{m}\right): m \geq n\right\}=0, \lim _{n \rightarrow \infty} \sup \left\{p\left(y_{n}, z_{m}\right): m \geq n\right\}=0, \lim _{n \rightarrow \infty} \theta\left(x_{n}\right.$, $\left.w_{n}, s_{n}, t_{n}\right)=0$ and $\lim _{n \rightarrow \infty} \theta\left(y_{n}, z_{n}, s_{n}, t_{n}\right)=0$ imply $\lim _{n \rightarrow \infty} \theta\left(w_{n}, z_{n}, s_{n}, t_{n}\right)=0$ or $\lim _{n \rightarrow \infty} \sup \left\{p\left(w_{m}, x_{n}\right): m \geq n\right\}=0, \lim _{n \rightarrow \infty} \sup \left\{p\left(z_{m}, y_{n}\right): m \geq n\right\}=0, \lim _{n \rightarrow \infty} \theta\left(x_{n}\right.$, $\left.w_{n}, s_{n}, t_{n}\right)=0$ and $\lim _{n \rightarrow \infty} \theta\left(y_{n}, z_{n}, s_{n}, t_{n}\right)=0$ imply $\lim _{n \rightarrow \infty} \theta\left(w_{n}, z_{n}, s_{n}, t_{n}\right)=0$.

$\left(u_{5}\right) \lim _{n \rightarrow \infty} \theta\left(w_{n}, z_{n}, p\left(w_{n}, x_{n}\right), p\left(z_{n}, x_{n}\right)\right)=0$ and $\lim _{n \rightarrow \infty} \theta\left(w_{n}, z_{n}, p\left(w_{n}, y_{n}\right), p\left(z_{n}, y_{n}\right)\right)=$ 0 imply $\lim _{n \rightarrow \infty} d\left(x_{n}, y_{n}\right)=0$ or $\lim _{n \rightarrow \infty} \theta\left(a_{n}, b_{n}, p\left(x_{n}, a_{n}\right), p\left(x_{n}, b_{n}\right)\right)=0$ and $\lim _{n \rightarrow \infty} \theta\left(a_{n}, b_{n}, p\left(y_{n}, a_{n}\right), p\left(y_{n}, b_{n}\right)\right)=0$ imply $\lim _{n \rightarrow \infty} d\left(x_{n}, y_{n}\right)=0$.

We recall remark, examples, definition and lemmas which will be useful in what follows.

Remark 2.1 ([13]) (a) Suppose that $\theta$ from $X \times X \times R_{+} \times R_{+}$into $R_{+}$is a mapping satisfying $\left(u_{2}\right) \sim\left(u_{5}\right)$. Then there exists a mapping $\eta$ from $X \times X \times R_{+} \times R_{+}$into $R_{+}$such that $\eta$ is nondecreasing in its third and fourth variable, satisfying $\left(u_{2}\right)_{\eta} \sim\left(u_{5}\right)_{\eta}$, where $\left(u_{2}\right)_{\eta} \sim\left(u_{5}\right)_{\eta}$ stand for substituting $\eta$ for $\theta$ in $\left(u_{2}\right) \sim\left(u_{5}\right)$, respectively.

(b) On account of (a), we may assume that $\theta$ is nondecreasing in its third and fourth variables, respectively, for a function $\theta$ from $X \times X \times R_{+} \times R_{+}$into $R_{+}$satisfying $\left(u_{2}\right) \sim\left(u_{5}\right)$.

(c) Each $\tau$-distance $p$ on a metric space $(X, d)$ is also a $u$-distance on $X$.

We present some examples of $u$-distance which are not $\tau$-distance (for details, see [13]).

Example 2.2 Let $X=R_{+}$with the usual metric. Define $p: X \times X \rightarrow R_{+}$by $p(x, y)=\left(\frac{1}{4}\right) x^{2}$. Then $p$ is a $u$-distance on $X$ but not a $\tau$-distance on $X$.

Example 2.3 Let $X$ be a normed space with $\|\cdot\|$, then a function $p: X \times X \rightarrow R_{+}$defined by $p(x, y)=\|x\|$ for every $x, y \in X$ is a $u$-distance on $X$ but not a $\tau$-distance.

It follows from the above examples and (c) of Remark 2.1 that $u$-distance is a proper extension of $\tau$-distance.

Definition 2.4 ([13]) Let $X$ be a metric space with a metric $d$ and let $p$ be a $u$-distance on $X$. Then a sequence $\left\{x_{n}\right\}$ in $X$ is called $p$-Cauchy if there exists a function $\theta$ from $X \times$ 
$X \times R_{+} \times R_{+}$into $R_{+}$satisfying $\left(u_{2}\right) \sim\left(u_{5}\right)$ and a sequence $\left\{z_{n}\right\}$ of $X$ such that

$$
\begin{aligned}
& \lim _{n \rightarrow \infty} \sup \left\{\theta\left(z_{n}, z_{n}, p\left(z_{n}, x_{m}\right), p\left(z_{n}, x_{m}\right)\right): m \geq n\right\}=0 \quad \text { or } \\
& \lim _{n \rightarrow \infty} \sup \left\{\theta\left(z_{n}, z_{n}, p\left(x_{m}, z_{n}\right), p\left(x_{m}, z_{n}\right)\right): m \geq n\right\}=0 .
\end{aligned}
$$

Lemma 2.5 ([13]) Let $X$ be a metric space with a metric $d$ and let $p$ be a $u$-distance on $X$. If $\left\{x_{n}\right\}$ is a p-Cauchy sequence, then $\left\{x_{n}\right\}$ is a Cauchy sequence.

Lemma 2.6 ([13]) Let $X$ be a metric space with a metric $d$ and let $p$ be a u-distance on $X$.

(1) If sequences $\left\{x_{n}\right\}$ and $\left\{y_{n}\right\}$ of $X$ satisfy $\lim _{n \rightarrow \infty} p\left(z, x_{n}\right)=0$ and $\lim _{n \rightarrow \infty} p\left(z, y_{n}\right)=0$ for some $z \in X$, then $\lim _{n \rightarrow \infty} d\left(x_{n}, y_{n}\right)=0$.

(2) If $p(z, x)=0$ and $p(z, y)=0$, then $x=y$.

(3) Suppose that sequences $\left\{x_{n}\right\}$ and $\left\{y_{n}\right\}$ of $X$ satisfy $\lim _{n \rightarrow \infty} p\left(x_{n}, z\right)=0$ and $\lim _{n \rightarrow \infty} p\left(y_{n}, z\right)=0$ for some $z \in X$, then $\lim _{n \rightarrow \infty} d\left(x_{n}, y_{n}\right)=0$.

(4) If $p(x, z)=0$ and $p(y, z)=0$, then $x=y$.

Lemma 2.7 ([13]) Let $X$ be a metric space with a metric d and let $p$ be a $u$-distance on X. Suppose that a sequence $\left\{x_{n}\right\}$ of $X$ satisfies

$$
\begin{aligned}
& \lim _{n \rightarrow \infty} \sup \left\{p\left(x_{n}, x_{m}\right): m>n\right\}=0 \quad \text { or } \\
& \lim _{n \rightarrow \infty} \sup \left\{p\left(x_{m}, x_{n}\right): m>n\right\}=0 .
\end{aligned}
$$

Then $\left\{x_{n}\right\}$ is a p-Cauchy sequence.

\section{Main result}

The following lemma plays an important role in proving our theorems.

Lemma 3.1 Let $(X, d)$ be a metric space with a u-distance $p$ on $X$ and $\left\{a_{n}\right\}$ and $\left\{b_{n}\right\}$ be sequences of $X$ such that

$$
\begin{aligned}
& \lim _{n \rightarrow \infty} \sup \left\{p\left(a_{n}, a_{m}\right): m>n\right\}=0 \quad \text { and } \\
& \lim _{n \rightarrow \infty} \sup \left\{p\left(a_{n}, b_{m}\right): m>n\right\}=0 .
\end{aligned}
$$

Then there exist a subsequence $\left\{a_{k_{n}}\right\}$ of $\left\{a_{n}\right\}$ and a subsequence $\left\{b_{k_{n}}\right\}$ of $\left\{b_{n}\right\}$ such that $\lim _{n \rightarrow \infty} d\left(a_{k_{n}}, b_{k_{n}}\right)=0$.

Proof Since $p$ is a $u$-distance on $X$,

there exists a mapping $\theta: X \times X \times R_{+} \times R_{+} \rightarrow R_{+}$

such that $\theta$ is nondecreasing in its third and

fourth variable respectively, satisfying $\left(u_{2}\right) \sim\left(u_{5}\right)$.

For each $n \in N$, let

$$
\alpha_{n}=\sup \left\{p\left(a_{n}, a_{m}\right): m>n\right\} \quad \text { and } \quad \beta_{n}=\sup \left\{p\left(a_{n}, b_{m}\right): m>n\right\} .
$$


By hypotheses and (3.2), we have

$$
\lim _{n \rightarrow \infty}\left(\alpha_{n}+\beta_{n}\right)=0
$$

Let $k_{1} \in N$ be an arbitrary and fixed element. Then, by $\left(u_{2}\right)$, for this $a_{k_{1}} \in X$ and $\varepsilon=1$, there exists $\delta_{1}>0$ such that

$$
|s|=s<\delta_{1}, \quad|t|=t<\delta_{1}, \quad y \in X \quad \text { imply } \quad \theta\left(a_{k_{1}}, y, s, t\right)<1 .
$$

By virtue of (3.3) and (3.4), for this $\delta_{1}>0$, there exists $M_{1} \in N$ such that

$$
n \geq M_{1} \quad \text { implies } \quad \alpha_{n}+\beta_{n}<\delta_{1}
$$

Let $k_{2} \in N$ be such that

$$
k_{2} \geq \max \left\{1+k_{1}, M_{1}\right\}
$$

Due to (3.6), we have

$$
k_{1}<k_{2} \quad \text { and } \quad k_{2} \geq M_{1} \text {. }
$$

From (3.4), (3.5), (3.6) and (3.7) we get

$$
\theta\left(a_{k_{1}}, a_{k_{2}}, \alpha_{k_{2}}+\beta_{k_{2}}, \alpha_{k_{2}}+\beta_{k_{2}}\right)<1
$$

In terms of $\left(u_{2}\right)$ and (3.6), for this $a_{k_{2}} \in X$ and $\varepsilon=\frac{1}{2}$, there exists $\delta_{2}>0$ such that $|s|=s<\delta_{2}$, $|t|=t<\delta_{2}, y \in X$ imply

$$
\theta\left(a_{k_{2}}, y, s, t\right)<\frac{1}{2} .
$$

In view of (3.3) and (3.9), for this $\delta_{2}>0$, there exists $M_{2} \in N$ such that

$$
n \geq M_{2} \text { implies } \quad \alpha_{n}+\beta_{n}<\delta_{2} .
$$

Let $k_{3} \in N$ be such that

$$
k_{3} \geq \max \left\{1+k_{2}, M_{2}\right\} .
$$

On account of (3.9), (3.10), (3.11), we obtain

$$
k_{2}<k_{3} \text { and } \theta\left(a_{k_{2}}, a_{k_{3}}, \alpha_{k_{3}}+\beta_{k_{3}}, \alpha_{k_{3}}+\beta_{k_{3}}\right)<\frac{1}{2} .
$$

Continuing this process, there exist a subsequence $\left\{a_{k_{n}}\right\}$ of $\left\{a_{n}\right\}$ and a subsequence $\left\{b_{k_{n}}\right\}$ of $\left\{b_{n}\right\}$ such that for all $n \in N$,

$$
\theta\left(a_{k_{n}}, a_{k_{n+1}}, \alpha_{k_{n+1}}+\beta_{k_{n+1}}, \alpha_{k_{n+1}}+\beta_{k_{n+1}}\right)<\frac{1}{n} .
$$


Using (3.2), (3.3) and (3.13), we know that

$$
\begin{aligned}
& \lim _{n \rightarrow \infty}\left\{\sup \left[p\left(a_{k_{n}}, a_{k_{m+1}}\right): m \geq n\right]\right\} \\
& \quad \leq \lim _{n \rightarrow \infty}\left\{\sup \left[p\left(a_{k_{n}}, a_{l}\right): l>k_{n}\right]\right\} \\
& \quad=\lim _{n \rightarrow \infty} \alpha_{k_{n}}=0 \text { and } \\
& \lim _{n \rightarrow \infty} \theta\left(a_{k_{n}}, a_{k_{n+1}}, \alpha_{k_{n+1}}+\beta_{k_{n+1}}, \alpha_{k_{n+1}}+\beta_{k_{n+1}}\right)=0 .
\end{aligned}
$$

Using (3.1), (3.2), (3.14) and putting $x_{n}=y_{n}=a_{k_{n}}, w_{m}=z_{m}=a_{k_{m+1}}$ and $s_{n}=t_{n}=\alpha_{k_{n+1}}+\beta_{k_{n+1}}$ in $\left(u_{4}\right)$, we deduce

$$
\begin{aligned}
& \lim _{n \rightarrow \infty} \theta\left(a_{k_{n+1}}, a_{k_{n+1}}, p\left(a_{k_{n+1}}, a_{k_{n+2}}\right), p\left(a_{k_{n+1}}, a_{k_{n+2}}\right)\right)=0 \quad \text { and } \\
& \lim _{n \rightarrow \infty} \theta\left(a_{k_{n+1}}, a_{k_{n+1}}, p\left(a_{k_{n+1}}, b_{k_{n+2}}\right), p\left(a_{k_{n+1}}, b_{k_{n+2}}\right)\right)=0 .
\end{aligned}
$$

Using (3.15) and putting $w_{n}=z_{n}=a_{k_{n+1}}, x_{n}=a_{k_{n+2}}$ and $y_{n}=b_{k_{n+2}}$ in $\left(u_{5}\right)$, we have

$$
\lim _{n \rightarrow \infty} d\left(a_{k_{n+2}}, b_{k_{n+2}}\right)=0
$$

Due to (3.13) and (3.16), there exist a subsequence $\left\{a_{k_{n}}\right\}$ of $\left\{a_{n}\right\}$ and a subsequence $\left\{b_{k_{n}}\right\}$ of $\left\{b_{n}\right\}$ such that

$$
\lim _{n \rightarrow \infty} d\left(a_{k_{n}}, b_{k_{n}}\right)=0
$$

Definition 3.2 Let $(X, d)$ be a metric space, $2^{X}$ be a set of all nonempty subsets of $X$ and $\mathrm{Cl}(X)$ be a set of all nonempty closed subsets of $X$. Let $T: X \rightarrow 2^{X}$. Then an element $z \in X$ is a fixed point of $T$ if $z \in T z$.

A mapping $T: X \rightarrow 2^{X}$ is called Kannan-type multi-valued $p$-contractive mapping if there exist a $u$-distance $p$ on $X$ and $r \in\left[0, \frac{1}{2}\right)$ such that

(i) $p\left(y_{1}, y_{2}\right) \leq r\left[p\left(x_{1}, y_{1}\right)+p\left(x_{2}, y_{2}\right)\right]$ for any $x_{1}, x_{2} \in X, y_{1} \in T x_{1}$ and $y_{2} \in T x_{2}$,

(ii) $T y \subseteq T x$ for all $x, y \in X$ with $y \in T x$.

In the next example we shall show that if $(X, d)$ is a complete metric space with a $u$-distance $p$ and a mapping $T: X \rightarrow \mathrm{Cl}(X)$ is not Kannan-type multi-valued $p$-contractive, in general, $T$ may have no fixed point in $X$.

Example 3.3 Let $X=[0,1]$ be a closed interval with the usual metric and $p: X \times X \rightarrow R_{+}$ and $T: X \rightarrow \mathrm{Cl}(X)$ be mappings defined as follows:

$$
\begin{aligned}
& p(x, y)= \begin{cases}2, & x=0, \\
x, & x \neq 0,\end{cases} \\
& T x= \begin{cases}\left\{\frac{1}{4}\right\}, & x=0, \\
{\left[\frac{x}{8(1+x)}, \frac{x}{4(1+x)}\right],} & x \neq 0 .\end{cases}
\end{aligned}
$$


Define $\theta: X \times X \times R_{+} \times R_{+} \rightarrow R_{+}$by

$$
\theta(x, y, s, t)=s
$$

for all $x, y \in X$ and $s, t \in R_{+}$.

From (3.18) and (3.20) easily we can obtain that $p$ is a $u$-distance on $X$.

In terms of (3.18) and (3.19), we have

$$
p\left(y_{1}, y_{2}\right) \leq \frac{1}{4}\left[p\left(x_{1}, y_{1}\right)+p\left(x_{2}, y_{2}\right)\right]
$$

for all $x_{1}, x_{2} \in X, y_{1} \in T x_{1}$ and $y_{2} \in T x_{2}$.

To show that (3.21) is satisfied, we need to consider several possible cases.

Case 1. Let $x_{1}=x_{2}=0$. Then $y_{1} \in T x_{1}=\left\{\frac{1}{4}\right\}, y_{2} \in T x_{2}=\left\{\frac{1}{4}\right\}$,

$p\left(y_{1}, y_{2}\right)=y_{1}=\frac{1}{4}, p\left(x_{1}, y_{1}\right)=2$ and $p\left(x_{2}, y_{2}\right)=2$ and

$\frac{1}{4}\left[p\left(x_{1}, y_{1}\right)+p\left(x_{2}, y_{2}\right)\right]=\frac{1}{4}[2+2]=1 \geq \frac{1}{4}=p\left(y_{1}, y_{2}\right)$. Thus

$p\left(y_{1}, y_{2}\right) \leq \frac{1}{4}\left[p\left(x_{1}, y_{1}\right)+p\left(x_{2}, y_{2}\right)\right]$.

Case 2. Let $x_{1}=0$ and $x_{2} \neq 0$. Then $y_{1} \in T x_{1}=\left\{\frac{1}{4}\right\}$,

$y_{2} \in T x_{2}=\left[\frac{x_{2}}{8\left(1+x_{2}\right)}, \frac{x_{2}}{4\left(1+x_{2}\right)}\right], p\left(y_{1}, y_{2}\right)=y_{1}=\frac{1}{4}$,

$p\left(x_{1}, y_{1}\right)=2$ and $p\left(x_{2}, y_{2}\right)=x_{2}$. Thus

$\frac{1}{4}\left[p\left(x_{1}, y_{1}\right)+p\left(x_{2}, y_{2}\right)\right]=\frac{1}{4}\left[2+x_{2}\right] \geq \frac{1}{4}=p\left(y_{1}, y_{2}\right)$.

Case 3. Let $x_{1} \neq 0$ and $x_{2}=0$. Then $y_{1} \in T x_{1}=\left[\frac{x_{1}}{8\left(1+x_{1}\right)}, \frac{x_{1}}{4\left(1+x_{1}\right)}\right]$,

$y_{2} \in T x_{2}=\left\{\frac{1}{4}\right\}, p\left(y_{1}, y_{2}\right)=y_{1} \leq \frac{x_{1}}{4\left(1+x_{1}\right)}, p\left(x_{1}, y_{1}\right)=x_{1}$

and $p\left(x_{2}, y_{2}\right)=2$. Thus

$\frac{1}{4}\left[p\left(x_{1}, y_{1}\right)+p\left(x_{2}, y_{2}\right)\right]=\frac{1}{4}\left[x_{1}+2\right] \geq \frac{x_{1}}{4\left(1+x_{1}\right)} \geq p\left(y_{1}, y_{2}\right)$.

Case 4 . Let $x_{1} \neq 0$ and $x_{2} \neq 0$. Then $y_{1} \in T x_{1}=\left[\frac{x_{1}}{8\left(1+x_{1}\right)}, \frac{x_{1}}{4\left(1+x_{1}\right)}\right]$,

$y_{2} \in T x_{2}=\left[\frac{x_{2}}{8\left(1+x_{2}\right)} \frac{x_{2}}{4\left(1+x_{2}\right)}\right], p\left(y_{1}, y_{2}\right)=y_{1} \leq \frac{x_{1}}{4\left(1+x_{1}\right)}$,

$p\left(x_{1}, y_{1}\right)=x_{1}$ and $p\left(x_{2}, y_{2}\right)=x_{2}$. Thus

$\frac{1}{4}\left[p\left(x_{1}, y_{1}\right)+p\left(x_{2}, y_{2}\right)\right]=\frac{1}{4}\left[x_{1}+x_{2}\right] \geq \max \left\{\frac{x_{1}}{4\left(1+x_{1}\right)}, \frac{x_{2}}{4\left(1+x_{2}\right)}\right\} \geq p\left(y_{1}, y_{2}\right)$. 
From $(3.18) \sim(3.25)$, we have

$$
p\left(y_{1}, y_{2}\right) \leq \frac{1}{4}\left[p\left(x_{1}, y_{1}\right)+p\left(x_{2}, y_{2}\right)\right]
$$

for all $x_{1}, x_{2} \in X, y_{1} \in T x_{1}$ and $y_{2} \in T x_{2}$.

But there exist $x=0 \in X$ and $y=\frac{1}{4} \in X$ with $y \in T x$ such that $T y=T \frac{1}{4}=\left[\frac{1}{40}, \frac{1}{20}\right] \nsubseteq\left\{\frac{1}{4}\right\}=$ $T 0$. Therefore $T$ is not Kannan-type multi-valued $p$-contractive and $T$ does not have a fixed point.

Using Lemma 3.1, we have the following main theorem.

Theorem 3.4 Let $(X, d)$ be a complete metric space and let $T: X \rightarrow \mathrm{Cl}(X)$ be a Kannantype multi-valued $p$-contractive mapping. Then $T$ has a unique fixed point in $X$.

Proof Let $a_{1} \in X$ be arbitrary, $a_{2} \in T a_{1}$ and $a_{3} \in T a_{2}$ be chosen. Since $T$ is Kannan-type $p$-contractive,

$$
p\left(a_{2}, a_{3}\right) \leq r\left[p\left(a_{1}, a_{2}\right)+p\left(a_{2}, a_{3}\right)\right]
$$

where $r \in\left[0, \frac{1}{2}\right)$.

From (3.27), we get

$$
p\left(a_{2}, a_{3}\right) \leq k p\left(a_{1}, a_{2}\right)
$$

where $k=\frac{r}{1-r} \in[0,1)$.

By (3.27) and (3.28), we obtain a sequence $\left\{a_{n}\right\}$ in $X$ such that

$$
a_{n+1} \in T a_{n} \quad \text { and } \quad p\left(a_{n+1}, a_{n+2}\right) \leq k p\left(a_{n}, a_{n+1}\right)
$$

for all $n \in N$.

By repeated application of (3.29), we have

$$
p\left(a_{n}, a_{n+1}\right) \leq k^{n-1} p\left(a_{1}, a_{2}\right)
$$

for all $n \in N$.

Now we shall know that $\left\{a_{n}\right\}$ is a Cauchy sequence.

Let $n, m \in N$ be such that $n<m$. Then, by virtue of (3.30), we deduce

$$
\begin{aligned}
p\left(a_{n}, a_{m}\right) & \leq p\left(a_{n}, a_{n+1}\right)+p\left(a_{n+1}, a_{n+2}\right)+\cdots+p\left(a_{m-1}, a_{m}\right) \\
& =\sum_{i=n}^{m-1} p\left(a_{i}, a_{i+1}\right) \leq \sum_{i=n}^{m-1} k^{i-1} p\left(a_{1}, a_{2}\right) \\
& \leq\left(\frac{k^{n-1}}{1-k}\right) p\left(a_{1}, a_{2}\right) .
\end{aligned}
$$

In view of (3.31), we get

$$
\lim _{n \rightarrow \infty} \sup \left\{p\left(a_{n}, a_{m}\right): m>n\right\}=0
$$


On account of Lemma 2.5, Lemma 2.7 and (3.32), $\left\{a_{n}\right\}$ is a Cauchy sequence in $X$. Since $X$ is complete, there exists $b_{1} \in X$ such that

$$
\lim _{n \rightarrow \infty} a_{n}=b_{1} .
$$

By the same method as that in (3.27) (3.33), there exists a sequence $\left\{b_{n}\right\}$ in $X$ such that

$$
b_{n+1} \in T b_{n} \quad \text { and } \quad p\left(b_{n}, b_{n+1}\right) \leq k^{n-1} p\left(b_{1}, b_{2}\right)
$$

for all $n \in N$.

Combining the hypothesis, (3.27), (3.28), (3.30), (3.31) and (3.34), we have

$$
\begin{aligned}
p\left(a_{n}, b_{m}\right) & \leq p\left(a_{n}, a_{m}\right)+p\left(a_{m}, b_{m}\right) \\
& \leq p\left(a_{n}, a_{m}\right)+r\left[p\left(a_{m-1}, a_{m}\right)+p\left(b_{m-1}, b_{m}\right)\right] \\
& \leq\left(\frac{k^{n-1}}{1-k}\right) p\left(a_{1}, a_{2}\right)+r\left[k^{m-2} p\left(a_{1}, a_{2}\right)+k^{m-2} p\left(b_{1}, b_{2}\right)\right] \\
& \leq\left(\frac{k^{n-1}}{1-k}\right) p\left(a_{1}, a_{2}\right)+k^{n-1} p\left(a_{1}, a_{2}\right)+k^{n-1} p\left(b_{1}, b_{2}\right) \\
& =k^{n-1}\left\{\left(\frac{1}{1-k}\right) p\left(a_{1}, a_{2}\right)+p\left(a_{1}, a_{2}\right)+p\left(b_{1}, b_{2}\right)\right\}
\end{aligned}
$$

for all $n, m \in N$ with $m>n$.

By (3.35), we have

$$
\lim _{n \rightarrow \infty} \sup \left\{p\left(a_{n}, b_{m}\right): m>n\right\}=0 .
$$

Due to Lemma 3.1, (3.32) and (3.36), there exist a subsequence $\left\{a_{k_{n}}\right\}$ of $\left\{a_{n}\right\}$ and a subsequence $\left\{b_{k_{n}}\right\}$ of $\left\{b_{n}\right\}$ such that

$$
\lim _{n \rightarrow \infty} d\left(a_{k_{n}}, b_{k_{n}}\right)=0
$$

On account of the hypothesis and (3.34), we obtain

$$
b_{n+1} \in T b_{1}
$$

for all $n \in N$.

By virtue of the hypothesis, (3.33), (3.37) and (3.38), we have

$$
b_{1} \in T b_{1} .
$$

Due to (3.39), $b_{1}$ is a fixed point of $T$. To prove the unique fixed point of $T$, let $c_{1}$ be another fixed point of $T$. Then

$$
c_{1} \in T c_{1}
$$


Since $T$ is Kannan-type multi-valued $p$-contractive, by (3.39) and (3.40), we have

$$
\begin{aligned}
& p\left(b_{1}, b_{1}\right) \leq r\left[p\left(b_{1}, b_{1}\right)+p\left(b_{1}, b_{1}\right)\right], \\
& p\left(c_{1}, c_{1}\right) \leq r\left[p\left(c_{1}, c_{1}\right)+p\left(c_{1}, c_{1}\right)\right], \\
& p\left(b_{1}, c_{1}\right) \leq r\left[p\left(b_{1}, b_{1}\right)+p\left(c_{1}, c_{1}^{\prime}\right)\right] .
\end{aligned}
$$

Since $r \in\left[0, \frac{1}{2}\right)$, from (3.41), (3.42) and (3.43), we get

$$
p\left(b_{1}, b_{1}\right)=p\left(c_{1}, c_{1}\right)=p\left(b_{1}, c_{1}\right)=0 .
$$

By virtue of Lemma 2.6 and (3.44), we have

$$
b_{1}=c_{1} .
$$

On account of (3.39), (3.40) and (3.45), $T$ has a unique fixed point.

Now we give an example to support Theorem 3.4.

Example 3.5 Let $X=[0,1]$ be a closed interval with the usual metric, and $p: X \times X \rightarrow R_{+}$ and $T: X \rightarrow \mathrm{Cl}(X)$ be mappings defined as follows:

$$
\begin{aligned}
& p(x, y)=x, \\
& T x=\left[0, \frac{1}{4} x\right] .
\end{aligned}
$$

Let $\theta: X \times X \times R_{+} \times R_{+} \rightarrow R_{+}$be as in (3.20). Then, due to (3.46), we easily can obtain that $p$ is a $u$-distance on $X$.

From (3.46), we have

$$
p\left(y_{1}, y_{2}\right) \leq \frac{1}{4}\left[p\left(x_{1}, y_{1}\right)+p\left(x_{2}, y_{2}\right)\right]
$$

for all $x_{1}, x_{2} \in X, y_{1} \in T x_{1}$ and $y_{2} \in T x_{2}$. To show that (3.47) is satisfied, let $x_{1}, x_{2} \in X$, $y_{1} \in T x_{1}$ and $y_{2} \in T x_{2}$. Then $p\left(y_{1}, y_{2}\right)=y_{1} \leq \frac{1}{4} x_{1}$ and $\frac{1}{4}\left[p\left(x_{1}, y_{1}\right)+p\left(x_{2}, y_{2}\right)\right]=\frac{1}{4}\left(x_{1}+x_{2}\right) \geq$ $\frac{1}{4} x_{1}$. Thus (3.47) is satisfied. Let $x, y \in X$ be such that $y \in T x$. Then $0 \leq y \leq \frac{1}{4} x$ and $T y \subseteq\left[0, \frac{1}{16} x\right] \subseteq\left[0, \frac{1}{4} x\right]=T x$. Thus $T y \subseteq T x$ for all $x, y \in X$ with $y \in T x$. Therefore all the conditions of Theorem 3.4 are satisfied and $T$ has a unique fixed point 0 in $X$.

Definition 3.6 Let $(X, d)$ be a metric space. A mapping $T: X \rightarrow X$ is called Kannan-type single-valued $p$-contractive mapping if there exist a $u$-distance $p$ on $X$ and $r \in\left[0, \frac{1}{2}\right)$ such that

(iii) $p\left(T x_{1}, T x_{2}\right) \leq r\left[p\left(x_{1}, T x_{1}\right)+p\left(x_{2}, T x_{2}\right)\right]$ for any $x_{1}, x_{2} \in X$,

(iv) if $\left\{x_{n}\right\}$ is a sequence in $X$ such that $x_{n+1}=T x_{n}$ for each $n \in N$ and $\lim _{n \rightarrow \infty} x_{n}=c \in X$, then $p(T c, c) \leq r[p(T c, T c)+p(c, T c)]$ and $p(c, T c) \leq r[p(T c, T c)+p(T c, c)]$.

In the following example we show that if $(X, d)$ is a complete metric space and a mapping $T: X \rightarrow X$ is not Kannan-type single-valued $p$-contractive, in general, $T$ may have no fixed point in $X$. 
Example 3.7 Let $X=[0,1]$ be a closed interval with the usual metric, and $p: X \times X \rightarrow R_{+}$ and $T: X \rightarrow X$ be mappings defined as follows:

$$
\begin{aligned}
& p(x, y)= \begin{cases}2, & x=0, \\
x, & x \neq 0,\end{cases} \\
& T x= \begin{cases}\frac{1}{4}, & x=0, \\
\frac{x}{4(1+x)}, & x \neq 0 .\end{cases}
\end{aligned}
$$

Define $\theta: X \times X \times R_{+} \times R_{+} \rightarrow R_{+}$by

$$
\theta(x, y, s, t)=s .
$$

By the same methods as in Example 3.3, we know that $p$ is a $u$-distance on $X$ and $T$ is not Kannan-type single-valued $p$-contractive and $T$ has no fixed point in $X$.

Theorem 3.8 Let $(X, d)$ be a metric space with a u-distance $p$ on $X$.

Let $T: X \rightarrow X$ be a Kannan-type single-valued p-contractive mapping such that there exist a sequence $\left\{x_{n}\right\}$ of $X$ and $c \in X$ satisfying $x_{n+1}=T x_{n}$ for each $n \in N$ and $\lim _{n \rightarrow \infty} x_{n}=$ $c \in X$. Then $c$ is a fixed point of $T$, i.e., $T c=c$.

Proof By hypotheses, we obtain

$$
\begin{aligned}
p(T c, T c) & \leq r[p(c, T c)+p(c, T c)]=2 r p(c, T c), \\
p(T c, c) & \leq r[p(T c, T c)+p(c, T c)] \\
& \leq r[2 r p(c, T c)+p(c, T c)] \\
& =r(2 r+1) p(c, T c), \\
p(c, T c) & \leq r[p(T c, T c)+p(T c, c)] \\
& \leq r\{2 r p(c, T c)+r(2 r+1) p(c, T c)\} \\
& =\left(2 r^{3}+3 r^{2}\right) p(c, T c) .
\end{aligned}
$$

Since $r \in\left[0, \frac{1}{2}\right), 2 r, r(2 r+1),\left(2 r^{3}+3 r^{2}\right) \in[0,1)$ and thus, by (3.51), (3.52) and (3.53), we have

$$
p(T c, T c)=p(T c, c)=p(c, T c) .
$$

In view of Lemma 2.6 and (3.54),

$$
T c=c .
$$

This means that $c$ is a fixed point of $T$.

Theorem 3.9 Let $(X, d)$ be a complete metric space and let $T: X \rightarrow X$ be a Kannan-type single-valued p-contractive mapping.

Then $T$ has a unique fixed point in $X$. 
Proof Since $T$ is Kannan type single-valued $p$-contractive, there exists a sequence $\left\{x_{n}\right\}$ of $X$ such that

$$
x_{n+1}=T x_{n} \quad \text { and } \quad p\left(x_{n+1}, x_{n+2}\right) \leq k p\left(x_{n}, x_{n+1}\right)
$$

for all $n \in N$, where $k \in[0,1)$.

By repeated application of (3.56), we have

$$
p\left(x_{n}, x_{n+1}\right) \leq k^{n-1} p\left(x_{1}, x_{2}\right)
$$

for all $n \in N$.

On account of (3.57), we get

$$
\begin{aligned}
p\left(x_{n}, x_{m}\right) & \leq p\left(x_{n}, x_{n+1}\right)+p\left(x_{n+1}, x_{n+2}\right)+\cdots+p\left(x_{m-1}, x_{m}\right) \\
& \leq \sum_{i=n}^{m-1} p\left(x_{i}, x_{i+1}\right) \leq \sum_{i=n}^{m-1} k^{i-1} p\left(x_{1}, x_{2}\right) \\
& \leq\left(\frac{k^{n-1}}{1-k}\right) p\left(x_{1}, x_{2}\right)
\end{aligned}
$$

for all $n, m \in N$ with $n<m$.

In view of (3.58), we deduce that

$$
\lim _{n \rightarrow \infty} \sup \left\{p\left(x_{n}, x_{m}\right): m>n\right\}=0 .
$$

By virtue of Lemma 2.5, Lemma 2.7 and (3.59), we know that $\left\{x_{n}\right\}$ is a Cauchy sequence.

Since $X$ is complete, there exists $c \in X$ such that

$$
\lim _{n \rightarrow \infty} x_{n}=c
$$

On account of the hypothesis, Theorem 3.8, (3.56) and (3.60), we know that $c$ is a fixed point, i.e.,

$$
T c=c .
$$

By the same method as that in (3.40) (3.45), we can prove that $T$ has a unique fixed point $X$.

From Theorem 3.9, we have the following corollary.

Corollary $3.10([1])$ Let $(X, d)$ be a complete metric space and let $T: X \rightarrow X$ be a mapping such that

$$
d(T x, T y) \leq r[d(x, T x)+d(y, T y)]
$$

for all $x, y \in X$ and some $r \in\left[0, \frac{1}{2}\right)$.

Then $T$ has a unique fixed point in $X$. 
Proof By the same methods as in (3.56) (3.59), we deduce that

$$
\lim _{n \rightarrow \infty} \sup \left\{d\left(x_{n}, x_{m}\right): m>n\right\}=0,
$$

where $x_{n+1}=T x_{n}$ for all $n \in N$.

Since $X$ is complete, there exists $c \in X$ such that

$$
\lim _{n \rightarrow \infty} x_{n}=c
$$

Due to the hypothesis and (3.62), we get

$$
\begin{aligned}
d\left(x_{n+1}, T c\right) & =d\left(T x_{n}, T c\right) \\
& \leq r\left[d\left(x_{n}, T x_{n}\right)+d(c, T c)\right] \\
& =r\left[d\left(x_{n}, x_{n+1}\right)+d(c, T c)\right]
\end{aligned}
$$

for all $n \in N$ and some $r \in\left[0, \frac{1}{2}\right)$.

Taking the limit as $n \rightarrow \infty$ in (3.64), we obtain

$$
d(c, T c) \leq r d(c, T c)
$$

for some $r \in\left[0, \frac{1}{2}\right)$.

From (3.65), we have

$$
d(c, T c)=0 .
$$

Since metric $d$ is a $u$-distance, by view of (3.62), (3.63), (3.66) and the hypothesis, conditions of Corollary 3.10 satisfy all conditions of Theorem 3.9.

Therefore $T$ has a unique fixed point.

Finally we shall present an example to show that all conditions of Theorem 3.9 are satisfied, but all conditions of Corollary 3.10 are not satisfied.

Example 3.11 Let $X=[0,1]$ be a closed interval with the usual metric, and $p: X \times X \rightarrow R_{+}$ and $T: X \times X$ be mappings defined as follows:

$$
\begin{aligned}
& p(x, y)=x, \\
& T x=\frac{1}{4} x .
\end{aligned}
$$

Then, due to (3.67), we easily can obtain that $p$ is a $u$-distance on $X$, but not metric and

$$
p(T x, T y) \leq \frac{1}{4}[p(x, T x)+p(y, T y)]
$$

for all $x, y \in X$.

Suppose that $\left\{x_{n}\right\}$ is a sequence of $X$ such that $x_{n+1}=T x_{n}$ for all $x \in N$. 
Then, by (3.67), we have

$$
x_{n+1}=T x_{n}=\frac{1}{4} x_{n}
$$

for all $n \in N$.

By virtue of (3.69),

$$
\lim _{n \rightarrow \infty} x_{n}=\lim _{n \rightarrow \infty}\left(\frac{1}{4}\right)^{n-1} x_{1}=0
$$

On account of (3.67) (3.70), all conditions of Theorem 3.9 are satisfied, but all conditions of Corollary 3.10 are not satisfied since $p$ is not metric.

\section{Competing interests}

The author declares that he has no competing interests.

\section{Author's contributions}

The author completed the paper himself. The author read and approved the final manuscript.

\section{Acknowledgements}

The author would like to express his gratitude to the referees for giving valuable comments and suggestions. This research was supported by Basic Science Research Program through the National Research Foundation of Korea (NRF) funded by the Ministry of Science, ICT \& Future Planning (2013R1A1A2057665).

\section{Received: 16 December 2014 Accepted: 23 February 2015 Published online: 11 March 2015}

\section{References}

1. Kannan, R: Some results on fixed points II. Am. Math. Mon. 76, 405-408 (1969)

2. Banach, S: Sur les opérations dans les ensembles abstraits et leur application aux équations intégrales. Fundam. Math. 3, 133-181 (1922)

3. Subrahmanyam, PV: Completeness and fixed-points. Monatshefte Math. 80, 325-330 (1975)

4. Naddler, SB Jr: Multi-valued contraction mappings. Pac. J. Math. 30, 475-488 (1969)

5. Ciric, LB: Fixed point theorems for multi-valued contractions in complete metric spaces. J. Math. Anal. Appl. 348, 499-507 (2008)

6. Dehaish, BA, Latif, A: Fixed point results for multivalued contractive maps. Fixed Point Theory Appl. 2012, 61 (2012)

7. Hirunworakit, S, Petrot, N: Some fixed point theorems for contractive multi-valued mappings induced by generalized distance in metric spaces. Fixed Point Theory Appl. 2011, 78 (2011)

8. Dehaish, BA, Latif, A: Fixed point theorems for generalized contractive type multi-valued maps. Fixed Point Theory Appl. 2012, 135 (2012)

9. Latif, A, Abdou, AAN: Fixed point of generalized contractive maps. Fixed Point Theory Appl. 2009, Article ID 487161 (2009)

10. Suzuki, T: Generalized distance and existence theorems in complete metric spaces. J. Math. Anal. Appl. 253, 440-458 (2001)

11. Suzuki, T, Takahashi, W: Fixed point theorems and characterizations of metric completeness. Topol. Methods Nonlinear Anal. 8, 371-382 (1996)

12. Kada, O, Suzuki, T, Takahashi, W: Nonconvex minimization theorems and fixed point theorems in complete metric spaces. Math. Jpn. 44, 381-391 (1996)

13. Ume, JS: Existence theorems for generalized distance on complete metric spaces. Fixed Point Theory Appl. 2010, Article ID 397150 (2010)

14. Vályi, I: A general maximality principle and a fixed point theorem in uniform spaces. Period. Math. Hung. 16, 127-134 (1985)

15. Wlodarczyk, K, Plebaniak, R: Maximality principle and general results of Ekeland and Caristi types without lower semicontinuity assumptions in cone uniform spaces with generalized pseudodistances. Fixed Point Theory Appl. 2010, Article ID 175453 (2010)

16. Wlodarczyk, K, Plebaniak, R: A fixed point theorem of Subrahmanyam type in uniform spaces with generalized pseudodistances. Appl. Math. Lett. 24, 325-328 (2011)

17. Wlodarczyk, K, Plebaniak, R: Kannan-type contractions and fixed points in uniform spaces. Fixed Point Theory Appl. 2011, 90 (2011)

18. Wlodarczyk, K, Plebaniak, R: Leader type contractions, periodic and fixed points and new completivity in quasi-gauge spaces with generalized quasi-pseudodistances. Topol. Appl. 159, 3504-3512 (2012)

19. Wlodarczyk, K: Hausdorff quasi-distances, periodic and fixed points for Nadler type set-valued contractions in quasi-gauge spaces. Fixed Point Theory Appl. 2014, 239 (2014) 